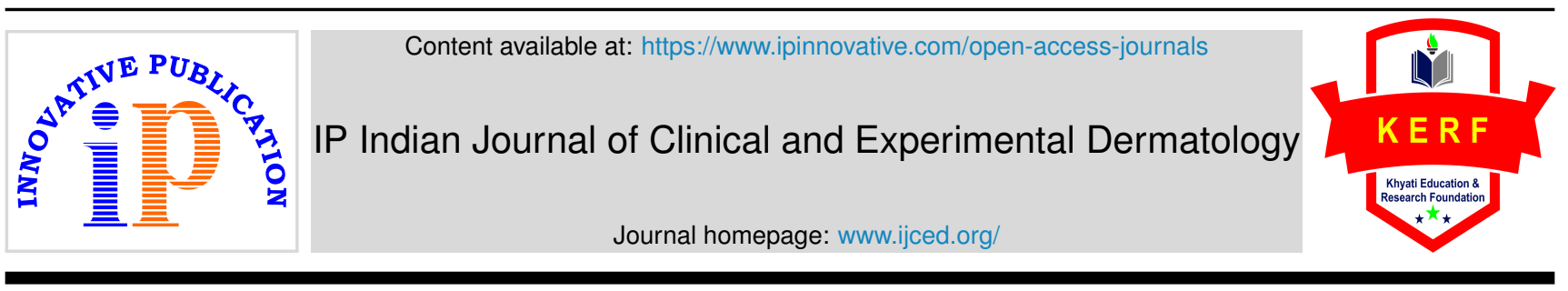

Original Research Article

\title{
Relative efficacy and safety of intralesional measles mumps rubella vaccine (MMR) and intralesional vitamin $D$ in multiple and recalcitrant verrucae vulgaris
}

\author{
Niharika Mittal ${ }^{1}$, SK Malhotra ${ }^{1, *}$, Navyug Raj Singh ${ }^{2}$ \\ ${ }^{1}$ Dept. of Dermatology and Venereology and Leprosy, Government Medical College, Amritsar, Punjab, India \\ ${ }^{2}$ Dept. of Pharmacology, Government Medical College, Amritsar, Punjab, India
}

\section{A R T I C L E I N F O}

\section{Article history:}

Received 07-05-2021

Accepted 19-05-2021

Available online 26-05-2021

\section{Keywords:}

Warts

Verrucae

Injection MMR

Vitamin D

\begin{abstract}
A B S T R A C T
Introduction: Verrucae or Warts are the viral infection of skin and mucosae caused by Human Papilloma Virus (HPV). Destructive modalities are the mainstay of treatment. They can have their own shortcomings like pain, infection, scarring and recurrence. To overcome these, immunotherapy is the emerging modality. Aims and Objectives: To study the relative efficacy and safety of intralesional Measles Mumps Rubella (MMR) vaccine and intralesional Vitamin D in the treatment of multiple and recalcitrant verruca vulgaris. Materials and Methods: 50 patients with multiple ( $>5)$ and recalcitrant warts were enrolled and divided randomly into two groups (Group A and Group B): In Group A, 25 patients were injected $0.3 \mathrm{ml}$ MMR vaccine whereas in Group B, 25 patients were injected $0.5 \mathrm{ml}$ Vitamin D injection after achieving anaesthesia with $0.2 \mathrm{ml}$ injection Lignocaine into the largest wart at 2 weeks interval until complete clearance or for maximum of 3 injections whichever was earlier. Patients were followed up fortnightly for 12 weeks.

Results: In Group A, 19 (76\%) patients showed Grade IV, 2 (8\%) patients had Grade III, 3 (12\%) patients had GII and only 1 (4\%) patient had Grade I improvement. In Group B on the other hand, 15 (60\%) patients showed Grade IV, 4 (16\%) patients had GIII, 4 (16\%) patients had Grade II and $2(8 \%)$ patients had Grade I improvement. None of the patients developed new lesions in both groups.

Conclusion: Both the immunotherapeutic treatments are safe, economic and less traumatic to the patients as compared to the destructive procedures for the treatment of warts.

(C) This is an open access article distributed under the terms of the Creative Commons Attribution License (https://creativecommons.org/licenses/by/4.0/) which permits unrestricted use, distribution, and reproduction in any medium, provided the original author and source are credited.
\end{abstract}

\section{Introduction}

Warts or verrucae are the benign epidermal proliferations of the skin or mucosae caused by viral infection with Human Papilloma Virus (HPV), a non enveloped double stranded DNA virus. ${ }^{1}$ It predominantly affects the young age group though no age group is spared. ${ }^{2}$ Warts are a major cause of cosmetic concern. Warts are mostly asymptomatic in nature, with tendency to spontaneously regress but it can spread to contagious areas along with symptoms like itching and pain especially in plantar and periungual warts, it can persist in a few patients affecting their quality of life and causing emotional, mental and social upset. ${ }^{3}$

\footnotetext{
* Corresponding author.

E-mail address: dskm50@gmail.com (S. K. Malhotra).
}

Destructive methods like use of salicylic acid, trichloroacetic acid, cryotherapy, laser ablation, electrocautery and radio frequency have been the mainstay of treatment for yearsbut these are painful, with high chances of secondary infection, scarring, high recurrence rate along with inability to treat multiple warts. ${ }^{4}$

To overcome these shortcomings, an effort to stimulate immune system against the pathogen via immunotherapy was tried with the help of various agents such as zinc sulfate, imiquimod, intralesional candida antigen, BCG vaccine, MMR vaccine, $P P D$, Vitamin D. ${ }^{5}$ These act via mounting delayed type hypersensitivity response and hence production of Th1 cytokines which in turn activate cytotoxic and Natural Killer cells and thence eliminate infection. These have the added benefit of clearing distant warts along 
with local lesions. ${ }^{6}$

In this present study, we attempted to evaluate the therapeutic efficacy and safety of two immunotherapeutic agents viz. intralesional MMR vaccine with that of intralesional Vitamin D in multiple and recalcitrant warts.

\section{Aims and Objectives}

1. To study the relative efficacy and safety of intralesional Measles Mumps and Rubella vaccine and intralesional Vitamin D in the treatment of multiple and recalcitrant verruca vulgaris.

2. To compare the clinical improvement in both the group after therapy

3. To evaluate the adverse effects associated with therapies used

\section{Materials and Methods}

This prospective study included 50 patients with multiple recalcitrant warts attending the outpatient clinic of the Department of Dermatology, Government Medical College, Amritsar after the approval of the Ethics Committee.

Patients who fulfilled the following criteria were included in the study:

1. Patients of both sexes between the ages 18-50 years

2. Patients having multiple verruca vulgaris ( $>5$ warts

3. Patients with duration of warts of three months or more or which were recalcitrant to other modalities.

The following patients were not included in the study:

1. Patients not willing to undergo the procedure

2. Patients of age $<18$ years and $>50$ years

3. Patients with warts other than verruca vulgaris

4. Immunocompromised patients/ patients with tuberculosis/ cutaneous malignancies/seropositive for $\mathrm{HIV} /$ hepatitis $\mathrm{B}$ / hepatitis $\mathrm{C} /$ diabetic patients.

5. Pregnant or lactating women

6. Patient with history of intake of immunomodulatory drugs

7. Patients with acute febrile illness

8. Patients with a history of convulsions, meningitis, asthma, allergic skin disorders and coagulopathies

9. Patients who have received any other treatment of warts in the last 1 month

After taking informed consent, thorough history was taken and clinical examination done to assess number, duration, location etc. of warts was done. Relevant investigations including complete blood count, bleeding time, clotting time, fasting blood sugar, liver function tests, renal function tests, viral markers were done. Patients were divided randomly into two groups-Group A and Group B of 25 patients in each.
Group A: Under all aseptic conditions, intralesional MMR vaccine $0.3 \mathrm{ml}$ using an insulin syringe was injected in the largest wart.

Group B: Under all aseptic conditions, intralesional Vitamin D $0.5 \mathrm{ml}(60,000 \mathrm{IU} / \mathrm{ml})$ using an insulin syringe was injected in the largest wart a few minutes after injecting lignocaine $0.2 \mathrm{ml}(20 \mathrm{ng} / \mathrm{ml})$ to alleviate the pain.

The procedure was repeated in the same lesion after every two weeks till complete clearance of warts was observed or for a maximum of three treatments in both the groups. Patients were followed up fortnightly for twelve weeks. Any untoward reaction/event reported by the patient was recorded and managed accordingly. Assessment of improvement was done with grading as follows:

1. Grade 0 Development of any new lesion and no response to therapy.

2. Grade $\mathrm{I}<25 \%$ response in old lesions.

3. Grade II $25 \%-50 \%$ response in old lesions.

4. Grade III $51 \%-75 \%$ response in old lesions.

5. Grade IV $>75 \%$ response in old lesions.

\section{Results}

50 patients with multiple and recalcitrant warts were included in the study and the improvement to treatment at all follow ups was graded, compared and analyzed by using Chi-square test and SPSS-22 version of software was used, released 2013, Armonk, NY: IBM Corp The following observations were made.

The demographic details of the patients in this study i.e. age, sex, occupation, residence along with duration, number and size of warts are as highlighted in Table 1.

In Group $\mathrm{A}$, at the end of the study i.e. after 12 weeks of follow up, majority of patients i.e. 19(76\%) patients showed Grade IV improvement while 2(8\%) had Grade III improvement, 3(12\%) patients had Grade II improvement and only 1(4\%) patient had Grade I improvement (Figures 1 and 2). None of the patients developed new lesions (Table 2). Complications reported were minimal i.e.11(44\%) patients developed pain during injection which persisted for a few hours, 2 (8\%) patients developed flu-like symptoms, 3(12\%) patients developed swelling at the site of injection and $2(8 \%)$ developed numbness at the site of lesions while $11(44 \%)$ patients did not develop any complications (Table 3 ).

In Group B, at the end of the study i.e. after 12 weeks of follow up, $15(60 \%)$ patients showed Grade IV while $4(16 \%)$ patients had Grade III improvement, 4(16\%) patients had Grade II improvement and $2(8 \%)$ patients had Grade I improvement (Figures 3 and 4). None of the patients developed new lesions (Table 2). All the patients i.e. $25(100 \%)$ patients developed pain during injection which persisted for a few hours and resolved on its own, 9(36\%) patients developed swelling, self limiting, at the site of 
injection and 2(8\%) patients developed erythema at the site of injection (Table 3).

On comparing improvement in both the groups, although clinical improvement was marginally more in case of Group A patients, it was not statistically significant (Figure 5).
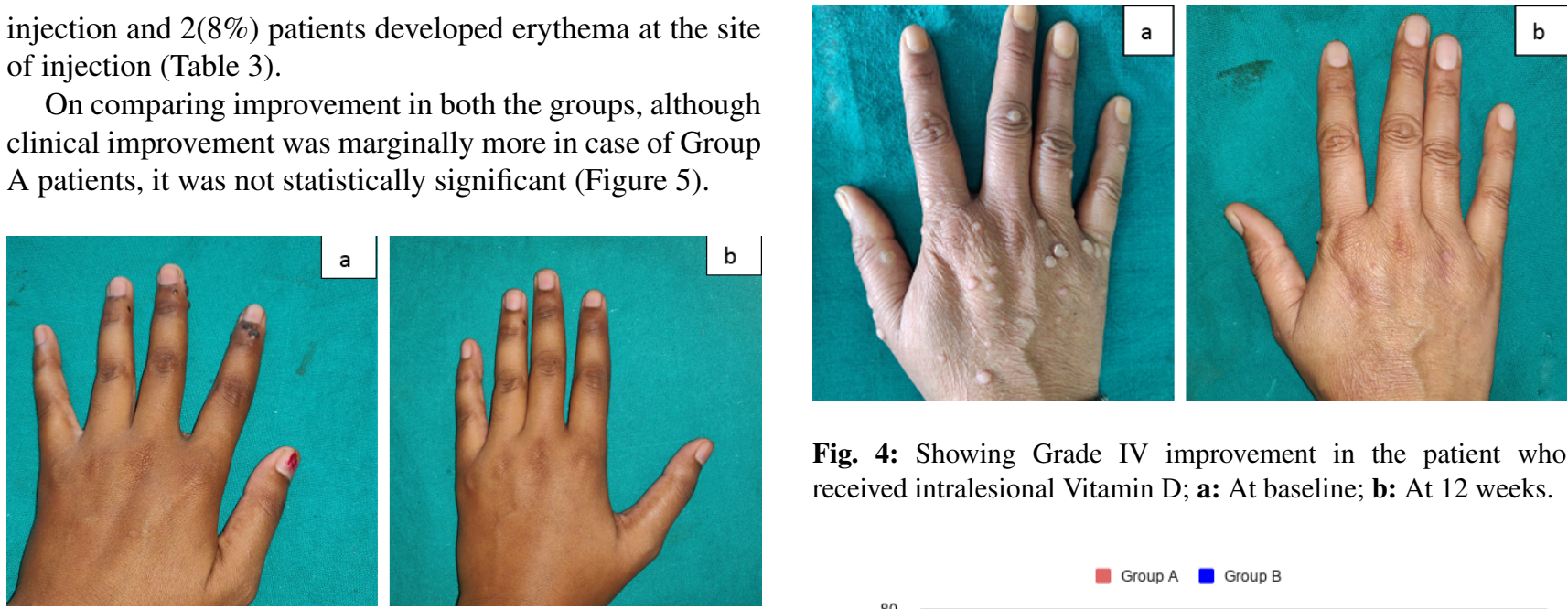

Fig. 4: Showing Grade IV improvement in the patient who received intralesional Vitamin D; a: At baseline; b: At 12 weeks.

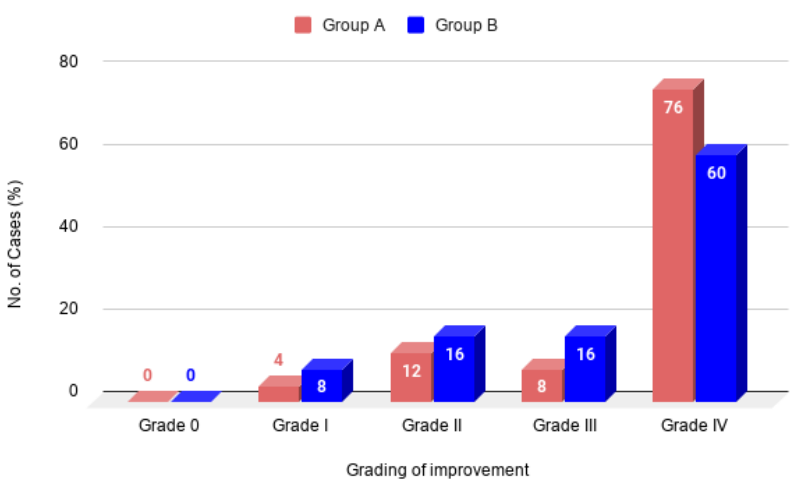

Fig. 5: Showing comparison in improvement in both the groups at end of study i.e. 12 weeks

Recurrence and resistance to therapy further adds to the agony of patients and physicians. There is no end to the ongoing search for a definitive cure of wart regardless of the presence of diverse therapeutic choices which also have side effects, though mild these can't be ignored. Thus strengthening the need of newer treatment modalities. Immunotherapy is such emerging modality which clears local as well as distant warts by increasing immune response against the pathogen. A number of antigens have been tried by researchers and in this present study, two such options are being evaluated.

In our study, in Group A, Grade IV improvement was noted in $76 \%$ patients while Grade III, Grade II and Grade I improvement was noted in $8 \%, 12 \%$ and $4 \%$ patients respectively. Findings in our study are consistent with other studies. Gamil et al (2010) studied 40 patients with plantar warts and injected MMR vaccine into the largest wart at 3week intervals until complete clearance or maximum of 3 treatments. Complete clearance of the warts was reported in $87 \%$, partial response in $4.3 \%$ and no response in $8.7 \%$. Similar results were reported by Nofal and Nofal (2010), ${ }^{7}$ Mohamad et al (2013) ${ }^{8}$ and Naseem and Aamir (2013) ${ }^{9}$ who reported complete response in $80 \%, 82 \%$

and $81.3 \%$ patients respectively whereas $\mathrm{Na}$ et al (2014)

Warts are notorious for their unpredictable course and they

are as likely to spontaneously regress as they are to persist.

Fig. 3: Showing Grade IV improvement in the patient who received intralesional Vitamin D; a: At baseline; b: At 12 weeks.

\section{Discussion}


Table 1: Demographic details of the patients in the study

$\begin{array}{lc}\text { Age (year) } & 30 \\ <30 & 20 \\ >30 & 29.00 \pm 9.16 \\ \text { Mean } \pm \text { SD } & 39 \\ \text { Sex } & 11 \\ \text { Male } & 35 \\ \text { Female } & 15 \\ \text { Residence } & 3-120 \\ \text { Urban } & 18.42 \pm 20.82 \\ \text { Rural } & 6-44 \\ \text { Duration of disease (months) } & 14.16 \pm 9.41 \\ \text { Min-Max } & 0.3-4 \\ \text { Mean } \pm \text { SD } & 2.21 \pm 1.84 \\ \text { Number of warts } & \\ \text { Min-Max } & 43 \\ \text { Mean } \pm \text { SD } & 6 \\ \text { Size of warts (cm) } & 6 \\ \text { Min-Max } & 1\end{array}$

Table 2: Grading of improvement at sixth visit (At 12 weeks)

\begin{tabular}{|c|c|c|c|c|c|c|}
\hline \multirow{2}{*}{$\begin{array}{l}\text { Grading of } \\
\text { improvement }\end{array}$} & \multicolumn{2}{|c|}{ Group A } & \multicolumn{2}{|c|}{ Group B } & \multicolumn{2}{|c|}{ Total } \\
\hline & No. & $\%$ & No. & $\%$ & No. & $\%$ \\
\hline 0 & 0 & 0.00 & 0 & 0.00 & 0 & 0.00 \\
\hline I & 1 & 4.00 & 2 & 8.00 & 3 & 6.00 \\
\hline II & 3 & 12.00 & 4 & 16.00 & 7 & 14.00 \\
\hline III & 2 & 8.00 & 4 & 16.00 & 6 & 12.00 \\
\hline IV & 19 & 76.00 & 15 & 60.00 & 34 & 68.00 \\
\hline Total & 25 & 100.00 & 25 & 100.00 & 50 & 100.00 \\
\hline
\end{tabular}

$\mathrm{X}^{2}: 1.613 ; \mathrm{df}: 3 ; \mathrm{p}=0.656$

Table 3: Complications in Group A and Group B

\begin{tabular}{|c|c|c|c|c|}
\hline \multirow[t]{2}{*}{ Complications } & \multicolumn{2}{|c|}{ Group A } & \multicolumn{2}{|c|}{ Group B } \\
\hline & No. of patients & $\%$ age & No. of patients & $\%$ age \\
\hline Pain during injection (persisting for few hours) & 11 & 44.00 & 25 & 100.00 \\
\hline Flu like symptoms & 2 & 8.00 & 0 & 0.00 \\
\hline Swelling at site of injection & 3 & 12.00 & 9 & 36.00 \\
\hline Numbness at site of injection & 2 & 8.00 & 0 & 0.00 \\
\hline Erythema at site of injection & 0 & 0.00 & 2 & 8.00 \\
\hline Nil & 11 & 44.00 & 0 & 0.00 \\
\hline
\end{tabular}


reported complete response in only $51.5 \%$ patients. ${ }^{10}$

However, on further evaluation by Shaheen et al (2015) who compared MMR with PPD, they found MMR to be better than PPD, with $60 \%$ response in the PPD group and $80 \%$ in the MMR group. ${ }^{11}$ The efficacy of MMR vaccine in warts was further strengthened by reports of Shah et al (2016), ${ }^{12}$ Dhope et al, (2017) ${ }^{13}$ and Pushpendra Singh et al (2019) ${ }^{14}$ who reported complete response in $72 \%$., $65 \%$ and $82.4 \%$ patients respectively.

Mechanism of intralesional injection of antigens may induce a potent nonspecific inflammatory response toward the cells which are infected by HPV. It has also been postulated that the trauma itself may lead to resolution of the wart in individuals with prior sensitization. It has been postulated to be related to the release of variable cytokines like TNF- $\alpha$, INF- $\gamma$, IL-2, IL-4, IL-5, and IL-8. ${ }^{15}$

In the present study, patients reported only mild complications i.e. majority of patients experienced pain, and a few developed flu like symptoms, swelling and numbness at the site of infection while $44 \%$ patients had no complications. Similar to our observation, pain and flu like symptoms are the most common complications reported by others. $^{7-14,16}$

In our study, in Group B, Grade IV was noted in $60 \%$ patients while Grade III, Grade II and Grade I improvement was noted in $16 \%, 16 \%$ and $8 \%$ patients respectively. These findings are in agreement with previous studies. Aktas et al (2015), studied twenty patients suffering from plantar warts. Vitamin D3 $(0.2 \mathrm{ml}, 7.5 \mathrm{mg} / \mathrm{ml})$ was injected into the base of the warts after prilocaine $(0.1 \mathrm{ml}, 20$ $\mathrm{mg} / \mathrm{ml}$ ) injection with maximum 2 injections given at 4week intervals. 16 of 20 patients $(80 \%)$ showed complete resolution of warts, and 1 patient showed partial resolution and 3 patients failed to show any response. ${ }^{17}$ Similar results were reported by Kavya et al, ${ }^{18}$ Fathy et al, ${ }^{19}$ Akula et al (2018) ${ }^{20}$ and Banoth (2019) ${ }^{21}$ who noted complete response in $78.57 \%, 70 \%, 70 \%$ and $76.92 \%$ patients. However higher results i.e $90 \%$ showed complete clearance in the study by Raghukumar et al (2017) ${ }^{22}$ whereas Kareem et al (2019) ${ }^{23}$ reported clearance in less number of patients i.e $40 \%$ showed complete clearance.

The effect of Vitamin D on warts was speculated to be derived from its potential to regulate epidermal cell proliferation as well as it's differentiation and modulate cytokine production. In addition, Toll like receptor activation of human macrophage upregulate the expression of Vitamin D receptor and Vitamin D hydroxylase genes, leading to expression and secretion of antimicrobial peptides. $^{24}$

In the present study, patients reported only mild complications i.e. all patients developed pain, while a notable number developed swelling at site and a few patients developed erythema at the site. Aktaş et al ${ }^{17}$ reported that only patient complaints were of minimal to moderate pain during injection. But in Kavya et al ${ }^{18}$ study, all side effects were minor and swelling was reported in $78.57 \%$ and also depigmentation in one patient.

On comparing intralesional MMR vaccine in Group A and intralesional Vitamin D in Group B, no significant difference was observed. This shows that intralesional injection of both have similar efficacy but discomfort, swelling are more pronounced with Vitamin D injection along with risks of local anaesthetic injection.

\section{Conclusion}

Both the immunotherapeutic treatments are safe, economic and less traumatic to the patients as compared to the destructive procedures. Both therapies have shown similar efficacy however clinical improvement was marginally more in case of intralesional MMR vaccine injection than the intralesional Vitamin D injection as well as ease with which the injection can be given in a busy outpatient department favours the former.

The limitations of our study were that firstly the sample size was small. Secondly, the patients with complete response were not graded separately. Also only patients with verruca vulgaris were included in the study and other types of warts were excluded from the study. Due to time constraints the follow up period of 12 weeks was short but since resolution or improvement can occur even after 12 weeks. Further studies consisting of a larger number of patients who should be followed up for longer periods of time to arrive at concrete conclusions regarding the efficacy and safety of these two modalities are suggested.

\section{Source of Funding}

No financial support was received for the work within this manuscript.

\section{Conflicts of Interest}

There are no conflicts of interest.

\section{References}

1. Lowy DR, Androphy EJ, Warts D. Warts. In: Freedberg I, Wolff K, et al., editors. Fitzpatrick's Dermatology in General Medicine, 5th edn. New York: McGraw Hill; 2003. p. 2119-31.

2. Kilkenny M, Marks R. The descriptive epidemiology of warts in the community. Australas J Dermatol. 1996;37(2):80-6. doi:10.1111/j.1440-0960.1996.tb01010.x

3. Bacelieri R, Johnson SM. Cutaneous warts: An evidence based approach to therapy. Am Fam Physician. 2005;72(4):647-52.

4. Lipke MM. An Armamentarium of Wart Treatments. Clin Med Res. 2006;4(4):273-93. ब01:103/2//cmr4.4.273

5. Goihman-Yahr M, Goldblum OM. Immunotherapy and warts: a point of view. Clin Dermatol. 2008;26(2):223-5. doi:10.1016/j.clindermatol.2007.10.01].

6. Horn TD, Johnson SM, Helm RM, Roberson PK. Intralesional Immunotherapy of Warts With Mumps, Candida, and Trichophyton Skin Test Antigens. Arch Dermatol. 2005;141(5):589-94.

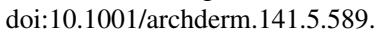


7. Nofal A, Nofal E. Intralesional immunotherapy of common warts: successful treatment with mumps, measles and rubella vaccine. $J$ Acad Dermatol Venereol . 2010;24(10):1166-70. doi:10.1111/.1468B083.200036-1.

8. Mohamad NS, Badran F, Yakout E. Evaluation of the efficacy of a combination - measles, mumps and rubella vaccine in the treatment of plantar warts. Our Dermatol Online. 2013;4(4):463-7. do1:0.724hourd20134.18

9. Naseem R, Aamir S. The efficacy of intralesional measles, mumps, rubella (MMR) antigen in treatment of common warts Pak. J Med Health Sci. 2013;(7):1130-3.

10. Na CH, Choi H, Song SH, Kim MS, Shin BS. Two-year experience of using the measles, mumps and rubella vaccine as intralesional immunotherapy for warts. Clin Exp Dermatol . 2014;39(5):583-9. dol:DIDICed.12369

11. Shaheen MA, Salem SAM, Fouad DA, El-Fatah AA. Intralesional tuberculin (PPD) versus measles, mumps, rubella (MMR) vaccine in treatment of multiple warts: a comparative clinical and immunological study. Dermatol Ther. 2015;28(4):194-200. 106:10.11/dth. 2230.

12. Saini S, Dogra N, Dogra D. A prospective randomized open label comparative study of efficacy and safety of intralesional measles, mumps, rubella vaccine versus $100 \%$ trichloroacetic acid application in the treatment of common warts. Int J Res Med Sci . 2016;p. 152933. doi:10.18203/2320-6012.1jrms20161223.

13. Chauhan PS, Mahajan VK, Mehta KS, Rawat R, Sharma V. The efficacy and safety of intralesional immunotherapy with measles, mumps, rubella virus vaccine for the treatment of common warts in adults. Indian Dermatol Online J. 2019;10:19-26.

14. El-Magiud E, El-Samea G, Hisham G. Intralesional Injection of Measles, Mumps, Rubella Vaccine versus Cryotherapy in Treatment of Warts: A Randomized Controlled Trial. Dermatol Ther.

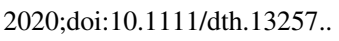

15. Gupta S, Malhotra AK, Verma KK. Intralesional immunotherapy with killed Mycobacterium w vaccine for the treatment of ano-genital warts: an open label pilot study. J Euro Acad Dermatol Venereol. 2008;22(9):1089-93.

16. Gamil H, Elgharib I, Nofal A, Abd-Elaziz T. Retraction notice to Intralesional immunotherapy of plantar warts: Report of a new antigen combination. J Am Acad Dermatol 2010;63:40-3. J Am Acad Dermatol. 2010;63(5):907. do1:10.1016/j.jaad.2010.09.001.

17. Aktas H, Ergin C, Demir B, Ekiz O. Intralesional - vitamin D injection may be an effective treatment option for warts. Cutan Med Surg. 2016;20:118-22.

18. Kavya M, Shashikumar BM, Harish MR, Shweta BP. Safety and efficacy of intralesional vitamin D3 in cutaneous warts: An open uncontrolled trial. J Cutan Aesthet Surg. 2017;10(2):90. doi:10.4103/jcas.jcas_82_16.

19. Fathy G, Sharara MA, Khafagyah. Intralesional vitamin D3 versus Candida antigen immunotherapy in the treatment of multiple recalcitrant plantar warts: A comparative case-control study. Dermatol Ther. 2019;p. 12997.

20. Akula ML, Shetty M, Shetty V, Patel P, Basil A. Comparative study of therapeutic efficacy of intralesional vitamin D3 versus intralesional purified protein derivative in the treatment of warts. Ind J Clin Exp Dermatol. 2018;4(3):226-31.

21. Banoth S. Evaluation of therapeutic effectiveness of vitamin D3 injections in common warts in a tertiary care centre. Int J Res Dermatol. 2019;5(3):462-5. 101:10.18203/1ssn.2455 4529.1ntjresdermato120192134.

22. Raghukumar S, Ravikumar BC, Vinay KN, Suresh MR, Aggarwal A, Yashovardhana DP, et al. Intralesional Vitamin D3 Injection in the Treatment of Recalcitrant Warts: A Novel Proposition. J Cutan Med

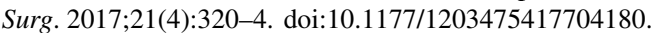

23. Kareem IMA, Ibrahim IM, Mohammed SFF, Ahmed AB Effectiveness of intralesional vitamin D3 injection in the treatment of common warts:Single-blinded placebo-controlled study. Dermatol Ther. 2019;32:12882.

24. Moscarelli L, Annunziata F, Mjeshtri A, Paudice N, Tsalouchos A, Zanazzi M, et al. Successful Treatment of Refractory Wart with a Topical Activated Vitamin D in a Renal Transplant Recipient. Case Rep Transplant. 2011;2011:1-3. [01:10. 155/200/368623.

\section{Author biography}

Niharika Mittal, Junior Resident

SK Malhotra, Professor

Navyug Raj Singh, Professor

Cite this article: Mittal N, Malhotra SK, Singh NR. Relative efficacy and safety of intralesional measles mumps rubella vaccine (MMR) and intralesional vitamin $\mathrm{D}$ in multiple and recalcitrant verrucae vulgaris. IP Indian J Clin Exp Dermatol 2021;7(2):158-163. 